\title{
Probative Blindness: How Safety Activity can fail to Update Beliefs about Safety
}

\author{
A J Rae*, J A McDermid ${ }^{\dagger}$, R D Alexander ${ }^{\dagger}$, M Nicholson $^{\dagger}$ \\ *Griffith University, Australia, ${ }^{\dagger}$ University of York, United Kingdom \\ Deramore Lane, Heslington, York, YO105GH john.mcdermid@york.ac.uk
}

Keywords: accident investigation, safety analysis

\begin{abstract}
Accidents are preceded by a period where, in hindsight, there was an opportunity to recognise and prevent the impending disaster. Various theories have attempted to describe and explain why warning signs are ignored. This paper examines the specific role of safety analysis as a warning mechanism. Depending on the context of the analysis, and the selection of activities, safety analysis may only serve to provide assurance of safety, even when such assurance is unwarranted. A better understanding of false assurance prior to accidents will allow for more appropriate selection, performance and interpretation of safety analysis methods and results.
\end{abstract}

\section{Introducing Probative Blindness}

Accidents occur when organisations enter a state involving unacceptable risk and are unable to navigate back to safer territory. Whilst some of these occasions may be ascribed to wilful risk-taking or powerlessness to halt the course of events, others involve a failure to use evidence to update beliefs about safety. If organisations cannot make the shift from believing that they are safe to recognising the unacceptable level of risk, they cannot take remedial action.

Many models for organisational safety incorporate this failure to belief-shift as an important factor. Turner describes the time before an accident as "disaster incubation" [1]. During disaster incubation evidence of safety problems is mounting, but the organisation is unable to recognise this evidence due to a form of bounded rationality. Vaughan introduces the concept of "normalisation of deviance" where warning signs become routine rather than alarming [2]. High Reliability Organisation (HRO) theorists such as La Porte point to a focus on "evidence that contradicts" as a feature that distinguishes safe from unsafe organisations [3].

It is easy to confuse failure to update beliefs with a lack of willingness or effort to engage in safety activities. Turner explicitly prescribes safety analysis as a solution to cultural blindness. Vaughan developed her theory explaining how beliefs about safety change over time, in contrast to a prevailing narrative about "amoral calculating managers" [4]. However, spending resources on safety does not, by itself, give an organisation the capability to reliably make beliefshifts.
Safety activities perform three broad purposes: ensurance (increasing the safety of a system), assurance (increasing confidence in the safety of a system) and assessment (determining the amount of safety risk). Whilst a single activity may serve multiple purposes - for example analysis often serves a dual role of finding problems and increasing confidence in their absence - in practice activities are seldom equally good at increasing and decreasing confidence in safety. In fact, assurance activities may at times make it harder to determine the safety of a system.

This paper is an investigation of how and why assurance activities can be unable to differentiate between safe and unsafe systems and situations. Of particular concern are activities which increase confidence in the safety of a system or situation, despite having very limited ability to cause a belief-shift when warranted. Such activities are evident, with hindsight, in many accidents. The Macondo Well blowout (Deepwater Horizon) featured tests of concrete setting which were repeated until they gave satisfactory values - the concern was to achieve a passed test, not to discover the state of the concrete [5]. The Nimrod XV230 crash featured a hazard log with un-examined hazards marked as closed - the concern was to achieve hazard closure, not to understand the remaining risk from the hazards [6]. The Hertfordshire Oil Storage Depot explosion and fire (Buncefield) featured a comprehensive safety report which had no influence on the actions of the operator or the regulator - the concern was to have a safety report, not to determine whether the depot was safe [7].

It would be naïve to expect that such circumstances are only present in accident scenarios, and not in other systems and operations. This is not to suggest that safety professionals are routinely indifferent to reality, nor does it deny the possibility that some accidents may result from genuine deception. However, there are numerous reasons why a proportion of safety effort will always be devoted to activities incapable of revealing reality.

We identify this phenomenon as "probative blindness". Whilst safety activities can be inherently non-probative (such as when the activity itself is focussed exclusively on ensurance), probative blindness more often occurs when otherwise probative activities are carried out with an inappropriate mindset, with insufficient competence, or in a context where their outputs will be ignored.

Typically, non-probative safety activities are performed to demonstrate safety to others or to reassure ourselves. They are 
performed when there is neither time nor budget to make changes to the design - there is an institutional assumption that analysis will show the system to be safe. This focus on demonstration is at best orthogonal, and in most cases actively contradicts the need to discover and communicate the hazards of the system and their remaining risk.

It is not the presence of non-probative activities alone which leads to danger. There are two differences between safe and unsafe organisations. The first difference is the nature of the underlying reality. If a system or practice is in fact safe, then the absence of activities which could reveal a lack of safety is not dangerous. This is cold comfort since there are many examples of unsafe organisations which believed the underlying reality to be one of safety. The second difference is the amount of non-probative activity and its interaction with probative activities. Non-probative safety work can be deadly when it distracts from, hampers, or actively prevents activities capable of revealing reality.

An alternate view of the same problem comes from the statistical method of Bayesian Inference [8]. A Bayesian approach draws a distinction between the world we are actually in, and the world we believe we are in. Bayes' Law provides a way of updating beliefs by combining the strength of existing beliefs ("priors") with the strength of new evidence. One implication of applying Bayesian Inference is that new evidence should be selected based on its power to resolve which world we are in (its probative value). Confirmation bias draws people to the opposite approach, selecting new evidence based on its consistency with the current hypothesis - i.e. looking for consequences that they would expect if their current beliefs were true rather than consequences that they would expect if their current beliefs were false. Such evidence has very little probative value.

\section{Explaining Probative Blindness}

What are the factors that make individuals and organisations reluctant to undertake activities likely to change their beliefs about the safety of a system or situation? We suggest four aspects of the activities where things can go wrong:

Safety activities can be requested without a strong intent to be probative.

This may be because of a strong belief that the system is safe, or because the safety activities are for purposes orthogonal to achieving safety. For example, the Nimrod Safety Management Plan of February 2002 stated:

"... there is a high level of corporate confidence in the safety of the Nimrod aircraft. However, the lack of structured evidence to support this confidence clearly requires rectifying, in order to meet forthcoming legislation and to achieve compliance."

In other words the plan was to produce evidence to support what everyone already "knew", which was that the aircraft was safe. The motivation was not safety itself, but compliance with legislation [6].
Safety activities can have probative intent by those who request them, but may be unable to uncover existing problems.

This may be due to the methods employed, or the competence and attitude of those engaged in the activities. For example, when staff planned the relocation of trailer accommodation at BP Texas City Refinery, they followed a procedure which mandated a siting analysis. This was intended to prevent placement of temporary structures within the blast zone of hazardous plant. They misunderstood both the purpose and nature of the analysis, and provided drawings showing where office equipment was to be located within the trailers [9].

The outcomes of potentially probative safety activities may be dismissed or discarded, even by those who requested the activities.

In such cases strong confirmation bias is at work; organisations are willing to accept evidence which accords with their current understanding, but find reasons to criticise or dismiss evidence which challenges their beliefs. The British government response to bovine spongiform encephalopathy (BSE), "mad cow disease", showed a strong inclination to use scientific uncertainty as a reason to reject analysis by its own agencies where the findings were contrary to the government's public position about BSE risk [10].

The status of safety practitioners within the organisation, their perceived competence, and their position as "insiders" or "outsiders" may all influence whether probative safety activities shift the beliefs of the organisation as a whole.

Organisations may initially accept the results of probative safety activities, but this acceptance is temporary and provisional.

Weak, non-probative evidence that the problem has been dealt with is accepted, allowing a return to previous beliefs about safety. Foam loss from the space shuttle external fuel tank, including loss of the specific bipod piece that led to the loss of Columbia, was repeatedly flagged as a problem, and then marked as resolved on the basis of dubious statistical analysis [11].

For the first two aspects, increasing the amount of safety activity is unlikely to result in safety improvement, since it does not address the underlying causes of the blindness. Extra activity is no more likely to be probative. For the third and fourth stages, it is plausible that a greater weight of evidence could force and preserve a belief shift, but disasters such as Deepwater Horizon [5], Bristol Royal Infirmary [12] and Fukushima [13] speak to the strength of the compulsion to dismiss evidence which causes cognitive dissonance, and to grasp at weak evidence which alleviates dissonance.

A better understanding of the phenomenon of probative blindness is necessary to build organisations which can select, apply and interpret safety analysis to align beliefs about safety with safety reality.

Probative blindness, as we have described it here, is an attractive explanation for observations made by ourselves and 
others. There are alternate explanations available for these same observations, including the possibilities that a simple lack of safety effort is causing the observed effects, or that failure to belief-update is an entirely cultural effect relating to lack of concern for safety.

In the remainder of this paper we consider how to test if probative blindness is a real phenomenon, and provide some results from preliminary testing.

\section{Testing for Probative Blindness}

\subsection{Overview}

Our testing method is based on a case study series. The term "case study" is often misapplied in safety research to refer to illustrative examples. Properly applied case studies, though, are the appropriate way of investigating a phenomenon in a real world context when the boundary between the phenomenon and its context is unclear [14]. The specific method to be employed is alternate theoretical templates, as described by Yin [14] and applied by Bitektine [15]. This approach requires multiple theories, with a clear statement of the hypotheses presented by each theory. Internal validity of the research is strengthened by acknowledging alternate explanations and looking for patterns associated with those alternatives. External validity comes from replicating the approach on multiple case studies to differentiate between features specific to one case and features general to many cases.

The overall questions to be answered are:

- Do accidents occur after organisations have failed to use evidence to update their beliefs about safety?

- If so, what role is played by safety analysis activities in this failure?

The unit of analysis for each case study is a single organisation which has experienced a multiple-fatality accident. Within each case study the embedded units are safety analysis activities. Each embedded unit begins with the earliest mention of the activity, and concludes either when there is no further discussion of the activity or its findings, or when the accident occurs, whichever is earlier.

\subsection{Predicted and alternate patterns}

Theoretical templates necessarily are blunt characterisations. No template will be a perfect fit for each case study, but the templates should be sufficiently distinct to allow investigators to agree which template applies.

All of the templates suggest that the accident will involve a number of proximate causal factors (PCFs) which existed within the organisation prior to the accident. The templates make different predictions about the organisational understanding of these factors.

The four main templates used in this work are summarised as:
Probative Blindness: An accident occurred despite significant safety effort and because the effort was unable to update beliefs about safety.

This template predicts that prior to the accident, the organisation spent considerable effort on safety analysis. Despite this, they did not recognise the PCFs as significant threats to safety. In hindsight, the safety analysis will have been unlikely to reveal the PCFs due to the way it was requested, conducted or interpreted.

The distinguishing feature of this template will be safety analysis which did not result in any organisational response that indicates appreciation of the nature or size of the threat.

Insufficient Safety Analysis: Safety analysis was unable to update beliefs because insufficient safety analysis was performed.

This template challenges the idea that reasonable attempts have been made to analyse safety. The template shares the prediction that the organisation did not recognise PCFs as significant threats to safety, but also predicts that there was a shortage of safety analysis. In hindsight, it is likely that more extensive safety analysis would have revealed the PCFs.

The distinguishing feature of this template will be identification of specific safety activities which were not conducted.

Aware but Powerless: The accident occurred despite belief update, and because of an inability to address identified problems.

This template challenges the importance of belief-update in preventing accidents. It predicts that the organisation did recognise the PCFs as significant threats, but was unsuccessful in responding to those threats. The template predicts sincere attempts to address the PCFs.

The distinguishing feature of this template will be actions that show both an awareness of each PCF and an intent to respond to the threat.

Lack of Concern: The accident occurred due a lack of concern for safety, reflected in both lack of safety analysis and lack of response to identified issues.

This template challenges the assumption common to the other templates that organisations genuinely want to reduce risk to levels that society considers acceptable. The template predicts both a shortfall in safety analysis and a lack of response to those issues that the organisation was aware of.

The distinguishing feature of this template will be actions which are consistent with being aware of PCFs but inconsistent with responding to the threat, such as conscious concealment.

\subsection{Source Interpretation}

The template descriptions here are summaries. The full templates include rules for interpreting the source documents. As an illustrative example, how should we judge whether NASA, as an organisation, appreciated the risk presented by 
the PCF, "Foam causing damage to space shuttle tiles" prior to the Columbia accident [11]?

Our search rules look for comments by decision makers recognising the PCF, comments minimising or dismissing it as a threat, actions that were consistent with the belief that it was a threat, and actions that were inconsistent with the belief that it was a threat.

In addition to distinguishing between the theoretical templates, the study also seeks to identify recurring themes associated with each hypothesis.

\section{Initial Findings about Probative Blindness}

\subsection{Deepwater Horizon / Macondo Well}

Deepwater Horizon was a re-locatable deep sea drilling rig operating at the newly prepared Macondo Well in the Gulf of Mexico. On April 20, 2010, an uncontrolled rush of hydrocarbons through the well (a "blowout") led to explosions and fires. There were eleven fatalities and the largest ever marine oil spill [5].

The three main PCFs leading to the accident were:

- The design of the production casing on the well floor, in particular impact this had on placing the cement barrier

- Failure to identify problems with the cement barrier immediately prior to the accident

- Failure of the Blowout Preventer (BOP) device

Commentary on the accident has focussed on the failures of BP (owners of the Macondo Well) and Transocean (operators of the Deepwater Horizon) to manage the risks associated with a blowout. This commentary implies either lack of concern or insufficient safety analysis (see e.g. the U.S. Department of the Interior report [16]).

It is indisputable that the three factors discussed here played a role in the accident. Each of the theoretical templates provides a different explanation for this role, and makes predictions accordingly.

The insufficient safety analysis template predicts the identification of specific safety activities that were not conducted, whilst the lack of concern template predicts actions consistent with being aware of a threat. The numerous investigations into Deepwater Horizon found no evidence matching these predictions. Instead, there is a consistent pattern of safety analysis being conducted, but failing to uncover the unsafe factors. This pattern matches the probative blindness template.

BP's initial design of the well was the subject of extensive analysis and review. Late changes were also carefully modelled and analysed. Whilst there is considerable criticism of the design in hindsight, there is no indication that the problems arose from lack of design or analysis effort [17].

To verify the integrity of the cement barrier, three separate "negative pressure tests" were conducted. These tests should have only been considered passed if there was no observed flow or pressure build-up. Rather than accept that the tests had failed, staff focussed selectively on evidence of success, and developed theories to explain away the symptoms of failure.

The blowout preventer was subject to intensive safety analysis. The control system alone was the subject of a 472 page quantitative risk assessment [18]. A detailed analysis of the blowout released in June 2014 determined that the true cause of BOP failure was likely to be missing from most analyses of similar systems [19]. Transocean's Major Hazard Risk Assessment for Deepwater Horizon showed a clear belief in the efficacy of the blowout preventer [19].

\subsection{New Orleans Hurricane Protection System}

On August 29, 2005, Hurricane Katrina struck the United States coastline. Of the over 1800 casualties, over 1500 occurred due to storm surges and flooding in and around New Orleans [20]. Whilst some casualties were expected from a storm the size of Katrina, "A large portion of the destruction from Hurricane Katrina was caused not only by the storm itself, however, but also by the storm's exposure of engineering and engineering-related policy failures" [21].

The hurricane protection system was established on a projectby-project basis. Failure of the system was not a result of complex interactions between these projects, however, but an accumulation of levees breaching at fifty distinct locations. It is useful to consider not just the causes of the overall system failure but the causes of individual breaches.

When examined at this level of detail, a consistent pattern emerges. Analysis was conducted for the purpose of design selection, not to assess the safety of designs. Nonconservative values were consistently selected. As examples:

- $\quad$ soil strength was overestimated;

- low target-factors of safety were selected;

- $\quad$ simplified, less-conservative soil models were used;

- a less-severe hurricane model was applied; and

- $\quad$ soil subsidence was ignored.

The American Society of Civil Engineers report [21] infers that "if a more rigorous analysis had been performed at the time of design, the potential problem would have been predicted and corrective action taken."

The pattern here closely fits both the probative blindness and the insufficient safety analysis templates. Significant safety analysis was conducted, but it failed to reveal the problems. There is no evidence that decision makers were aware of the problems, and a large number of indications that safety was an important consideration (the whole protection system was a response to an environmental threat, not a profit-making business controlling hazards of its own making).

There are conflicting indications as to whether the problems related to the context of the safety analysis, or the amount of analysis. Within the same documents are discussions about political and funding considerations driving the outcomes of 
analysis, and suggestions that more comprehensive risk assessment would have revealed the problems.

\subsection{BP Texas City Refinery Explosion}

On March 23, 2005, an explosion occurred in an isomerisation unit (ISOM) at the BP refinery in Texas City, Texas. Isomerisation is the process of converting straightchain hydrocarbon molecules into higher-octane isomers. Part of this process, the separation of lighter and heavier molecules, occurs in towers called raffinate splitters. During start-up of the ISOM, one of the raffinate splitters overfilled, releasing a geyser of flammable liquid. There were 180 injuries and fifteen fatalities. All of the fatalities occurred in or near office trailers which had been sited too close to the ISOM.

The immediate causes of the accident were [9]:

- The ISOM startup procedure was performed incorrectly, causing the tower to overfill

- The physical condition of the alarms and indicators did not warn the operators that the tower was overfilling

- The design of the ISOM, including the indicators, the relief valve system, the blow-down capacity and the lack of a flare provided insufficient protection in the event of an overfill

- Occupied trailers were located too close to the ISOM

- Non-essential personnel were not removed from the area during the start-up operation

Numerous other factors appear within the U.S Chemical Safety and Hazard Investigation Board report [9], but they are indirect - they contributed to one or more of the immediate causes.

Our early study of this accident revealed details which appeared to support the idea of probative blindness at work. For example, the office trailers were located close to the ISOM after a siting safety analysis - the purpose of which was totally misunderstood by the staff who executed it.

However, systematic application of the templates to all of the available information falsified this initial impression.

The first three immediate causes, along with most indirect causes associated with them, follow the pattern of "aware but powerless". In each case there is substantial evidence that management was aware of the problems, and was making effort to address them. There is some evidence to suggest that management believed they had "turned a corner"; they incorrectly believed that they were successful in alleviating the problems. This false assurance came from inappropriate safety measurement (in particular measuring personal injury outcomes rather than major hazard risk) rather than from safety analysis activity.

The fifth immediate cause - failure to remove non-essential personnel - may have been alleviated if a "pre-startup safety review" (PSSR) had been conducted. This is a match against the "insufficient safety analysis" pattern. However, the absence of PSSR is itself symptomatic of the incorrect start- up procedure, related to indirect causes such as competence, supervision and procedural compliance which had been identified and which management were trying to address.

Overall we concluded that this accident was not an example of probative blindness. It shows both that the theory is not universally applicable (not all accidents involve probative blindness) and also that it is falsifiable in specific cases (it is possible to determine the absence of probative blindness).

\subsection{Fukushima Daiichi Explosions}

The nuclear accident that began with an earthquake and Tsunami off the coast of Fukushima on 11 March 2011 appears a prime candidate for testing the alternate templates. The protection of the reactors at Fukushima Daiichi against both seismic shock and tsunami flood were the subject of separate safety analyses which did not result in design improvement.

Fukushima was originally designed against a seismic event of 265 Gal. In 1981 and again in 2006 new Japanese standards for seismic protection were introduced, and plants were required to re-assess against the new standard (a "seismic back check"). The back-check for Fukushima implausibly reported protection against $600 \mathrm{Gal}$, indicating analysis conducted for the purpose of showing that the targets were met, rather than discovering whether they were met.

Whilst revised assessment of the potential size and effect of a tsunami did reveal that a tsunami could exceed initial design assumptions, this finding did not lead to remedial action.

The Independent Commission report [22] describes the regulator and operators of Fukushima as being aware of the unsafe factors. However, the report shows a consistent pattern of seeking evidence to confirm beliefs that the factors were not true threats.

"For example, NISA informed the operators that they did not need to consider a possible station blackout (SBO) because the probability was small and other measures were in place. It then asked the operators to write a report that would give the appropriate rationale for why this consideration was unnecessary. " [22]

The Independent Commission clearly doubted the sincerity of the regulator and operator beliefs. Unfortunately, the publicly available records report the commission's assessment of what the regulator and the operator should have believed, rather than what they actually reported when interviewed. There is a clear assumption of malfeasance, with insufficient detail for $3^{\text {rd }}$ party research to distinguish between the alternate explanations of probative blindness and lack of concern.

This is particularly important since, as explained by Downer [13], the malfeasance explanation allows other nuclear states to remain confident in their own assurance, denying themselves an opportunity for belief-shift.

\section{Discussion}


This investigation forms one element of a full explanation for why accidents occur. False assurance from safety activities is a theme within a broader pattern of organisations failing to update their beliefs in the face of warning signals. There are other themes in this pattern such as a failure to measure safety performance, failing to learn from precursor events, and failing to digest information from outside the organisation.

As shown by the BP Texas City Refinery case study, failure to update beliefs is not a necessary element of all accidents, although even there it is arguable that the extent of the risk was not fully appreciated.

The primary contribution of our work so far is to present the concept of probative blindness in such a way that it can be falsified, with a method capable of finding where it is not a good explanation. This allows us to explore the limits of its applicability. In contrast, study of HROs suffers from an inability to reliably identify HROs [23]. Study of Normal Accidents suffers from the un-falsifiable definition of Normal Accidents [24].

Probative blindness, and the problem of belief-update more generally, builds upon existing understanding of accidents as the result of forces other than malfeasance or incompetence. Only through this understanding can those who are neither evil nor incompetent avoid similar mistakes.

\section{References}

[1] B. A. Turner, 'The Organizational and Interorganizational Development of Disasters', Adm. Sci. Q., vol. 21, no. 3, pp. 378-397, 1976.

[2] D. Vaughan, The Challenger Launch Decision: Risky Technology, Culture, and Deviance at NASA, 1 edition. Chicago: University Of Chicago Press, 1997.

[3] T. R. La Porte, 'High Reliability Organizations: Unlikely, Demanding and At Risk.', J. Contingencies Crisis Manag., vol. 4, no. 2, p. 60, Jun. 1996.

[4] D. Vaughan, 'Theorizing Disaster: Analogy, historical ethnography, and the Challenger accident', Ethnography, vol. 5, no. 3, pp. 315-347, 2004.

[5] Committee for Analysis of Causes of the Deepwater Horizon Explosion, Fire, and Oil Spill to Identify Measures to Prevent Similar Accidents to the Future; National Academy of Engineering and National Research Council, Macondo Well-Deepwater Horizon Blowout: Lessons for Offshore Drilling Safety. Washington, D.C.: The National Academies Press, 2011.

[6] C. Haddon-Cave, 'The Nimrod Review: An Independent Review into the Broader Issues Surrounding the Loss of the RAF Nimrod MR2 Aircraft XV230 in Afghanistan in 2006', 282009.

[7] Buncefield Major Incident Investigation Board, 'The Report of the Buncefield Major Incident Investigation Board into the policy and procedures of the Health and Safety Executive's and the Environment Agency's role in regulating the activities on the Buncefield site under the COMAH Regulations', Health and Safety Executive, 2012.
[8] C. A. Cornell, 'Bayesian Statistical Decision Theory and Reliability-Based Design', Struct. Saf. Reliab., no. 254, 1972.

[9] U.S. Chemical Safety and Hazard Investigation Board, 'BP Texas City Investigation Report: Refinery Explosion and Fire', 2005-04-I-TX, Mar. 2007.

[10] Unión Europea, Comisión Europea, and D. G. Gee, Late lessons from early warnings: the precautionary principle 1896-2000. Luxemburgo: Oficina de Publicaciones Oficiales de las Comunidades Europeas, 2001.

[11] Columbia Accident Investigation Board, 'Columbia Accident Investigation Board', National Aeronautics and Space Administration, Aug. 2003.

[12] B. J. Kewell, 'Language games and tragedy: The Bristol Royal Infirmary disaster revisited', Health Risk Soc., vol. 8, pp. 359-377, Dec. 2006.

[13] J. Downer, 'Disowning Fukushima: Managing the credibility of nuclear reliability assessment in the wake of disaster', Regul. Gov., p. n/a-n/a, Aug. 2013.

[14] R. K. Yin, Case Study Research: Design and Methods: (Applied Social Research Methods, Volume 5): 005, Third Edition. Sage Publications, Inc, 2003.

[15] A. Bitektine, 'Prospective Case Study Design: Qualitative Method for Deductive Theory Testing', Organ. Res. Methods, Jul. 2007.

[16] Bureau of Ocean Energy Management Regulation and Enforcement, 'Report Regarding the Causes of the April 20, 2010 Macondo Well Blowout', U.S. Department of the Interior, Sep. 2011.

[17] F. H. Bartlit, 'Chief Counsel's Report - Chapter 4.2: Well Design', National Commission on the BP Deepwater Horizon Oil Spill and Offshore Drilling, 2011.

[18] EQE International, 'Risk Assessment of the Deepwater Horizon Blowout Preventer (BOP) Control System', Cameron Controls Corp, EQE Project Number 253150, Apr. 2000.

[19] U.S. Chemical Safety and Hazard Investigation Board, 'Explosion and Fire at the Macondo Well', Government Printer, 2010-10-I-OS, Jun. 2014.

[20] R. D. Knabb, J. R. Rhome, and D. P. Brown, 'Tropical Cyclone Report: Hurricane Katrina 23-30 August 2005', National Hurricane Center, Dec. 2005.

[21] C. F. Andersen, American Society of Civil Engineers, and Hurricane Katrina External Review Panel, The New Orleans hurricane protection system: what went wrong and why : a report. Reston, Va.: ASCE, 2007.

[22] K. Kurokawa, 'The Fukushima Nuclear Accident Independent Investigation Commission', The National Diet of Japan, 2012.

[23] A. Hopkins, 'The Problem of Defining High Reliability Organisations', Natl. Res. Cent. Occup. Saf. Health Regul. January, 2007.

[24] A. Hopkins, 'Was Three Mile Island a "Normal Accident"?', J. Contingencies Crisis Manag., vol. 9, no. 2, pp. 65-72, Jun. 2001. 